\title{
Exploring Hurdles Associated with the Orientation of Freshmen in the Institutions of Higher Learning. The Case of Two Former Black Universities in South Africa
}

\author{
Prof. S. M Kang'ethe \\ University of Fort Hare, Department of Social Work and Social Development \\ Box X1314, Alice 5700, South Africa \\ Email: skangethe@ufh.ac.za \\ Dr Patricia Muhuro
}

Senior Consultant, Teaching and Learning Centre, University of Fort Hare

Email: pmuhuro@ufh.ac.za

Doi:10.5901/mjss.2014.v5n23p1242

\section{Abstract}

Students' orientation is an important strategy for acclimatizing new student to the higher education milieu. However, the challenge of ever burgeoning cases of student dropout raises questions on whether higher education institutions are adequately acquainting new students to the institutional demands and realities. The purpose of the study was to explore hurdles associated with the orientation of new entrants to institutions of higher learning. Case studies of two universities in South African higher education students whose student bodies are largely first generation and from low socio-economic backgrounds were adopted. Such students have a dire need for orientation programmes. Data were collected through interviews, and semi structured questionnaires and document analysis. Participants for the study consisted of 220 first year students who responded to a semi-structured questionnaire. Also 4 staff responsible for the running of student orientation programs were purposively selected to participate in semi structured interviews. The data was triangulated to determine emerging themes. The study findings revealed the following hurdles emanating pertaining to orientation program: communication challenges, inconsistent enforcement of policies and lack of co-operation among stakeholders and poor understanding of the purpose of orientation, and negative attitudes of students towards orientation programmes. The study recommends a comprehensive approach where all the stakeholders should be made aware of orientation and also take active part in the design of the programme activities so as to own the programme and its goals.

Keywords: Hurdles, orientation, freshmen, higher education, social milieu, stakeholders, program ownership, drop out

\section{Background and Introduction}

In any occupational setting, putting in place techniques, procedures and interventions that makes new entrants to acclimatize to the institutional social milieu remains one of the desirable goals of the institutional operations and management. Likewise in educational settings, norms, cultures and expectations of higher education may differ from students' prior high school settigns and their home communities (Longden, 2004; Modipane, 2011). These conflicting environments place students' emotional and social wellbeing in danger. This therefore obligates student orientation programmes to be designed to ensure that the new higher education entrants are well received, are made to feel at home and get to understand the operations of the higher education systems within the least time span possible (Poirieir, Santanello \& Gupcchup,2007; Honkimäki \& Kálmán, 2012). This places the role of student orientation as a strategy to communicate expectations and norms in order to ensure student institutional fit (Upcraft, Gardiner \& Barefoot \& Associates, 2005). This is because students who have a clearer appreciation of the structures and processes of their insitutions are most likely to develop emotional and social satisfaction which enhance their sense of belonging and positive identity with the institution (Tinto, 1998; Terrenzini \& Pascarella, 2005). Thus, as noted by Mullendore \& Banahan, (2005) , an effective and efficient orientation programme is a sure way of achieving transition goals.

Apparently, orientation programmes are not always adequately conceptualised. While orientation programs ought to prepare students for future experiences they will encounter during their stay in hgiher education ( Newmnan-Gonchar, 2000; Upcraft et al., 2005), at times information may not fully reach the intended people. This causes a large number of new students to take time to familiarise themselbves with the basic processes, key insitutional places to get help and to acquire functional literacies to make them succeed in their studies. The delayed acclimatisation may contribute to 
student dropout as students feel isolated and perplexed. In South African higher education, higher dropout rates of first time higher education entrants which is curretly about one third of those enrolled each year is a cause for concern (Scott, Hendry \& Yield, 2007; CHE, 2009). Given that students who are admitted to higher education are selected based on their pass rates and potential to succeed (DoE, 2005), it can be argued that some transition challenges could be making a bigger contribution to the dropouts. The study is concerned with finding out the hurdles that higher learning insitutions are encountering as they attempt to support student transition through student orientation programms. The findings could assist in coming up with improved ways of implementing orientation programmes so as to imptove students' retention and success.

Realistically, one of the major success of a good orientation programe is one that ensures that all the targeted personalities attend the sessions and fully benefit from the programmed activities. However, in some cases, new students and even staff participantion in orientation can be an eminent challenge. To this end, UNESCO (2002) observed that in most educational institutions, most orientation programmes arespearheaded by the student affairs division of the university, and as such most segments of the university do not feel obliged to play an active role in orientation program. If this happens in any setting, students may not fully grasp the academic, social and psychologicla benefits that orientation goals aim to achieve. Yet, Mayhew, ,Vanderlinden \& Kim (2010).) and found that institutional wide participation and concern for orientation positively influence students' outcomes.

Obligation wise, orientation programmes should familiarise students to academic demands of higher education such as information literacy skills, study skills, reading and writing conventions and effective study strategies. In order to achieve this, the activities should offer spaces for authentic experiences. According to Kramer \& Wasburn (1983), a successful orientation programme must be circumspectly designed with learning materials that address key transititonal needs of diverse students. Apart from enabling new entrants to intermingle with older community members in the insititution as a way to build social and academic networks, orientation must enhance the development of soft skills such as teamwork, self regulation, goal setting and career choice, managing time, adopting effective learning strategies, conflict resolution and emotional intellingences. In view of the critical role of orientation programmes in higher education, the current study found it worthwhile to empirically explore any imminent gaps some institutions of higher leaning could be facing in the implementation of their orientation programmes.

\section{Problem Statement}

Orientation, whether viewed from global, regional and national contexts is a phenomenon employed by social institutions in acclimatizing new workers, students apprentices so that they can understand policies, programmes and procedures of how these social institutions operate (Upcraft et al., 2005). It is therefore important that the orientation program is well grounded in terms of preparations, resources, and objectives to ensure that the new initiates adapt to the new social milieu within the shortest time span (Mullendore \& Banahan, 2005). These researchers' subjective observations and supported by both desk top and empirrical literatute seem to suggest that the majority of students in some universities take time to acclimatise and this could possibly be the main cause for high drop outs during the first year of their study. It is therefore critical that empirical investigations in these institutions' orientation programmes are pursued with the hope of pinning down the possible gaps and possibly working to fill them. This, these researchers hope could lower the drop rate experienced by most freshment in the two institutions of learning under the study.

\section{Study Settings and Methods}

\subsection{Research Paradigm and Design}

The study employed a mixed method research approach embedded in the post posivist paradigm. According to Teddlie and Tashakkori(2009), mixed method research is beneficial in that quantitative and qualitative data are intergrated in one study. Cresswell(2009), contend that mixed method is beneficial in that the weaknesses on one research method is countered by the other methods. In this study, concurrent triangulation of reseach instruments helped to unearth the hurdles associated with implementing student orientation programmes. On specific design, the study used both case studies and mini surveys. Importantly, mixed method is favourable because it connects theory and practice and improves uncover multiple causalities in a phenomenon (Cresswell, 2009). A pragmatic stance was adopted in that the research objectives determined the type of data to be collected (Maree, 2007). 


\subsection{Research Methods}

Specifically, the study employed questionnaire interviews, document analysis and indepth interviews. The document analysis ensured that the researchers obtained description of trends, frequencies and interrelationships among the various activities done in the program including statistical analysis (Bergman, 2008). Document analysis enabled scrutiny of less subjective information through analysis of orientation program activities, plans and reviews. However, the principal researcher was aware of the flaws of document analysis with respect to currency of information, accessibility of confidential data which could result in misleading data and possibly affect the study results (Babbie, 2010). Therefore, data from document analysis was corroborated with findings from semi structured questionnaire interviews. These methods provided a quick way to collect both qualitative and quantitative data from many first year students on their views of orientation programs implementation.

The study also employed in-depth interviews with staff spearheading orientation programs. The intervews also allowed probing in order to clarify issues. This is in line with Teddlie and Tashakkori(2009) idea of involving multiple sources of evidence as a means to improve credibility of the findings.

\subsection{Sampling Frame}

The sampling frame composed of lists of staff working in different programs and the list of students registered with these two universities. Precisely, the sampling frames for the study were forty two thousand students and approximately six thousand staff members.

\subsection{Unit of Analysis}

The unit of analysis for the study constituted of students and a few staff working in the student orientation program. All the information sought in the study centred around the purpose, processes, and practices used when implementing the orientation program in the two institutions. Therefore, four student orientation co-ordinators and 220 students provided the required data.

\subsection{Sample selection and procedures}

The four staff participants who responded to interviews were purposively sampled from those leading student orientation initiatives in the institution. Purposive sampling was a cost effective method of collecting data from individuals possessing typical characteristics of the issue under investigation (Drew et al., 2008). On the other hand, 220 student participants were randomly sampled and 159 responded to the semi-structured questionnaires on orientation programs. According to Johnson \& Christensen (2012), simple random sampling allows the researcher to select the most accessible participants representing the diversity of the population. This participant had experience in the implementation of the orientation program.

\section{Research Domain}

Although there are twenty three public universities in South Africa, the study was mainly interested in universities located in rural settings and usually dominated by the black students or historically disadvantaged students.. Specifically, the research site comprised of two universities that were conveniently sampled from the twenty three public universities in South Africa. The selection criteria considered was rural location, willingness of the institutional administrators to participate in the study, and being a predominantly a black University.

These universities were chosen as research domain because of their administrations' willingness to be investigated. Most predominantly black Universities in South Africa still draw the majority of their students from rural and peri-urban communities (Strydom et al. 2010). These students are less likely to have adequate access to information about the higher education environment There is therefore a huge need for intensive orientation for them to feel comfortable in the higher education settings ( Modipane, 2011).

Precisely, the characteristic of being a rural university implies that a large number of none traditional students such as first generation, mature students, non-resident students are admitted. Also students from rural communities usually have academic and socio-econmic needs that need to be immediately addressed if they are to expeditiously pursue their education. This characteristic may imply that the majority of the students may not be well prepared for higher education 
due to the limited availability of learning resources (Longden, 2004; Letseka \& Breier, 2007). Therefore, most of the students are likely to have adjustment problems as the key potential dropout risk factor, hence orientation is key and paramount.

\section{Ethical and Legal Considerations}

Letters of permission obtained from the research ethics committees of the two institutions were used to gain access to the research respondents and participants. Apart from the permission from the gatekeepers, permission was also sought from each of the participants who voluntarily participated in the study (Silverman, 2011). This was achieved though a letter explaining the purpose of the study and an accompanying consent form to confirm willingness to participate. The principal researcher upheld the confidentiality of participants by using codes and pseudonyms when presenting and reporting on the data (Bergman, 2008). Participants were not compelled to disclose information. Interviews were tape recorded pending approval and consent of the respective respondents. The principal researcher took notes of instances where participants rejected to be voice recorded.

\section{Data Analysis and Interpretation}

The data was analysed inductively. This means that emerging themes were coded, and placed into appropriate categories. Data was presented using verbatim responses where appropriate.

\section{Data Credibility and Trustworthiness}

Trustworthiness has to deal with the way the researcher claims that the research is "worth paying attention to" or accurate (Leedy \& Ormroid, 2010). This was achieved through tape-recording interviews so as to capture full details of the conversations. In instances where the respondents were uncomfortable to be recorded, field notes were used (Bergman, 2008). The use of multiple methods also ensured that the weakness of one method was countered by other methods. The questionnaire was also reviewed by peers before administration so as to pick up on errors.

\section{Limitations of the Study}

There are many approaches used when implementing orientation programs (Upcraft et al., 2006). Therefore, findings concerning the challenges that are encountered in the implementation of orientation programs may be confined to a specific approach as well as the institutional context. Also data for the current study was collected in 2012 and therefore there is a high probability that the same conditions were largely prevalent. However, some of the findings are still beneficial for the improvement of orientation programs among those institutions still adopting a traditional orientation model. The other limitation is that interviews were conducted with four administrators involved in student orientation and students, but omitted the other staff who could also provide useful information to enrich the study findings.

\section{Findings}

\subsection{Poor student Attendance}

A document analysis of the first year students' attendance to orientation showed than less than half of the enrolled students fully attended all the scheduled activities. This is despite the fact that the prospectus and policy documents emphasise that orientation is compulsory for all new entrants. This raises a question on whether the students have been fully sensitized of the importance of attending the program. The fact that very few students attended the program over so many years may imply that many students have taken this program for granted. Out of the sampled 220 first year students who were enrolled in 2012, only $50(22.7 \%)$ had attended the orientation. This implies that more than three quarters of the students who participated in the study did not gain from the orientation program objectives of such as being introduced to important personality and getting to know important sites in the institution, or largely acculturating them to the higher education environment generally. This scenario is detrimental to student grounding which later influences students' performance. This is because they may fail to access university resources that are at their disposal due to lack of knowledge. Since orientation is offered before commencement of official classes in the two institutions, some students might have reasoned that orientation was not part of their classes and ignored it. It also emerged that the 
poor attendance was attributed to institutional related challenges.

\title{
9.2 Poor communication gap
}

Empirical findings indicated that the there was apparently a communication gap between the institution and the prospective students and other stakeholders. This is because information was sent through a handbook posted to the address provided to the students and yet it is apparent that most students did not read the handbook. This is supported by the following sentiments expressed by one of the orientation officials.

\begin{abstract}
We post offer letters and all the requisite orientation Information to all the students using the addresses they furnished our office.( OR_ADM1)

What is sent to the student is a handbook that contains all the dates pertaining to orientation and activities that the students are to be involved in (OR ADM_4)

My observation is that although you students receive handbooks outlining orientation dates admission, staff often receive phone inquires asking about the same things that are explained in the handbook (OR_ADM3)

The admission office sends students a short messaging system (sms) informing the students all the requisite orientation and admission status, but apparently not all the sms get through. Apparently, some students change phones and its difficult to get most recent contacts before they register. This impacts on our orientation program because fewer students attend. (OR-ADM1)
\end{abstract}

The above responses showed that the information dissemination to prospective students was done through printed handbooks and a short messaging system. However, it appeared that the printed mode did not necessarily benefit most students as they either never read or did not understand the contents of the guide. It seems that there could be a poor reading culture among most students, especially the printed materials. It is also possible that very few students really read completely the contents of the offer letters that were sent to them with guidelines on policies and procedures. If this is the case, then that could explain their ignorance about orientation as highlighted in the foregoing findings. These researchers are also of the opinion that the posting method used may not be ideal for most students of the current generation who are immensely inclined to the use of electronic communication as opposed to printed mode, even though they come from rural settings. It appears that the institutions are wasting resources by printing and posting guides which are minimally used by the students.

The poor students attendance to orientation indicated above could also be attributed to poor arrangement in terms of the timing of the implementation of the orientation program. For instance findings indicate that the orientation program is implemented once a week before the institutions officially opens. During this period, some students are still held in other institutional registration obligations

\subsection{Poor timing of the orientation}

The poor student attendance to orientation indicated above could also be attributed to poor arrangement in terms of the timing for the implementation of the orientation program. For instance findings indicate that the orientation program is implemented one week before the institutions officially opens. During this period, some students are still held in other institutional registration obligations. For example findings from the student participants revealed they were still sorting out their admissions and other admission challenges when the orientation was going on. The following are sentiments expressed by students as to the reasons why they could not attend the orientation.

\begin{tabular}{lcc}
\hline Aspect & Response & $\%$ \\
\hline Still finishing course selection and admission & 60 & $38 \%$ \\
Didn't have the bursary money to register yet & 46 & $29 \%$ \\
Was too confused to locate the venues for orientation & 11 & $8 \%$ \\
Did not know the orientation dates & 9 & $5 \%$ \\
I was still looking for permit & 6 & $3 \%$ \\
Still looking for accommodation & 27 & $17 \%$ \\
Total & 159 & $100 \%$ \\
\hline
\end{tabular}

As can be noted from the table above, findings from the first year students show that $60(38 \%)$ of the students failed to attend orientation due to course selection processes. This is probably those students who had not undergone clear career guidance and were on the fence regarding their desired career choices. Delays in course selection could also 
imply that such students did not attain good passes and were therefore being tossed from pole to pillar. The other 46(29\%) were still finalizing their bursary requirements, and 27 (17\%) were still searching for accommodation. This implies that at this time, most students had equally competing aspects to attend.

\title{
9.4 Inadequate time to allocated to orientation sessions
}

The findings point to the fact that orientation programs lasted for less than a week in the institutions under study. This limited the time required to address some of the topics which needed a longer time to teach. This view was expressed in the response below:

\begin{abstract}
Sometimes we have topics that need more than one hour session to tackle. We encourage the presenters to introduce the key aspects and probably conduct detailed workshops with the students during the course of the year. What we don't know is whether all students are able to take part in those follow up workshops. For example I think issues of stress management, conflict management and study skills need to be given much attention to most of our students"
\end{abstract}

I feel that our orientation program has focused too much on the social side of things at the expense of academic issues. These students come out of orientation without knowing their own learning styles and how to study effectively. The presentors sometimes just highlight the different ways, so some students come out of orientation without a full grasp of issues.

The responses above show that the time allocated to address some topics is not adequate to fully address topics that are important for first year students. This perhaps explains why some students may still be confused even after attending orientation. The limited time could also cause the program presenters to try to give a lot of information in a short space of time and this could increase the level of confusion due to information overload.

\section{Discussion of the Findings}

The study on the implementation of student orientation programs was premised on the assumption that students encounter many challenges when they enter the higher education setting. Retention scholars argue that the support structures inside the institution are crucial for enhancing student socialisation, engagement and retention (Pascarella and Terrenzini, 2005; Kuh, 2008; Strydom et al., 2010). In this study, the demographic information revealed that the majority of the students were non traditional, as evidenced by 159 (72.3\%) first generation students who registered. Therefore, their participation in orientation was crucial for their adaptation to higher education requirements. To this end, Pascarella and Terrenzini ( 2005) assert that student interaction with the university community during the early days significantly shape new student personal goals and aspirations, as well as make them acquire a laconic sense of belonging and build social networks. This means that such motivation initiatiated at orientation also enhance self confidence and esteerm. This concurs with the views postulated by Wonsoek ( 2007) that students who have a clear understanding of the insitutional processes develop increased confidence, social and emotional satisfaction, and a sense of belonging. Furthermore, students who attend orientation become assertive irrespective of gender, social, economic or ethnic background (Tinto; 2005; Pascarella \& Terenzini, 2005).

However, the findings indicated a gloomy picture on the relevance of orientation programs. This was because few students attended orientation. This was despite the fact that institutional policies in the two institutions emphasised orientation to be a compulsory programs for all incoming students. The orientation program was made compulsory based on the assumptions that all new students experience personal, social and psychological stresses when they enter a new environment. Therefore, orientation was aimed at acclimatising students so that they quickly acquaint themselves to higher education demands ( Crossling et al, 2008). The poor orientation attendance implies poor operalisation of the program. This also points to serious challenges in the enactment of policy in the institutions under study. To this end, Tinto (2005) points out that successful student retention strategy ensure that there is alignment between institutional policies and practices. In this study, it seems that the policy on orientation did not fully take into account the nature of the institutions' admission practice in relation to orientation programming. For instance there seemed to be no strategy to deal with students who missed orientation. Also, another hurdle noted was that the model that was used was not fully addressing students' needs.

The study also found out that orientation duration of one week was inadequate. This time allocation was traditional all the year round and conformed to the traditional model. Challenges associated with this model is that very little time is given to fully address topics. Therefore, there is a tendency for information overload as many presenters attempt to cover 
a lot of topics over a short period of time. This was unfair and unrealistic because most of the students were very unfamiliar with most issues that pertaining to higher education. Thus, the traditional model does not provide opportunity for students to fully internalise information, nor to develop the practical competencies that may be required. Probably the career choice challenges that most of the students expereince during the first year of study could be a sign of non participation in orientation programs as well as not fully understanding the key issues. Since empirical research elsewhere proves that students who participate in orientation have higher chances of being retained into second and third year after controlling demographics, schooling and gender variables (Upcraft et al., 2005), the scenario above already shows a gloomy picture of the potential of most students in the two institutions to be retained. Similarly, South African scholars have also found that those students who fail to adapt to the new demands are likey to drop out within the first year of their study (Letseka \& Maile ,2008 Scott, Yeld and Hendry, 2007). Further studies could determine whether there is a corelationship bewtween student career indecision and attending orientation.

It appears as if the communication and marketing channels used to disseminate information about orientation were not adequately appropriate to most students. Therefore, very few accessed the information meant to assist them. However, literature points out to the need of using various modes of communication to market orientation programs (Mullendore \& Banahan, 2005). Communication about orientation was mostly done through a printed handbook posted to students as part of their admission package. However, orientation staff pointed out students often called the administration office requesting orientation details which in fact was included in the handbook. Thos could possibly point to a problem of poor reading culture among most students. Even though there is a general observation that the English language command by most students is poor since it's not their mother tongue, it is possible that the majority of students from rural communities are usually affected because most of the teachers in these communities prefer to teach students in their mother tongue. Therefore, the assumption that students who were sent handbooks could understand English could be challenged. The fact that most students still did not read the handbooks shows the diminishing popularity of print media. This finding may therefore mean that the institutions under study have to use alternative marketing and information dissemination strategies for orientation in order to reach students in big numbers. Perhaps sending out audio and video clips explaining about the orientation program on the cell phones or through social media such as facebook, twitter and google could reach most of the young people much faster than the current modes. To this end, Kramer \& Wasburn (1983) as outline six attributes of a successful orientation programme. Among these attributes include issues of ensuring that the program meets the characteristics of the various students enrolling in higher education, careful planning of learning materials and enhancing functional competencies. Additionally, Thomas (2002) also assert that student participation in orientation can be erratic if there is a clash between orientation and other activities that students perceive as important for their wellbeing. In this study, it appears that competing demands presented another reason for students attendance to the orientation. Crossling et al. (2008) recommend that orientation should be conducted at a time when all the registration processes are complete. Perhaps these two institutions have to reconsider introducing first year seminars or extended orientation programs so that they are able to cater for their diverse clientele. First year seminars have the advantage that they are spread over a longer period of time.

Researchers have also found that the the first three weeks are a crucial moment for students who enter higher education because it is a period to make critical decisions (Siedman, 2005). It is therefore very important that the orientation program is admistered during this period, and has a component of decision making and goal setting. In this study, the findings suggest that the timing of the orientation program was usuitable bacuse of the clash between orientation and other important student commitments. This means that students who missed orientation may take a longer time to accustom to their new institutional environments, and probably struggle in setting realistic goals for their lives and careers.

Another possible hurdle in the implementation of orientation program was the low the socio economic status of most students. The findings revealed that some of the students did not have registration fees or were still sorting out financial issues by the time orientation commenced. Given the above reality, it may be necessary for the institutions to revisit the commencement dates for orientation to ensure that the majority of the students are served. However, there appears to be little suggestion from the literature on how to deal with such an aspect. Perhaps an extended orientation program spreading the orientation activities over several weeks or months could benefit most of the students.

Similarly, a gap noted in the current study was that few orientation staff had further contact with students beyond the orientation week. This means that the social networks formed during the orientation sessions are not formally sustained. Perhaps extending orientation activities could ensure prolonged engagement. Orientation can however only service student needs as far as aclamatising, but may not assist students in finding a solution to the emotional challenges they may be experiencing during the priod of transition. Also understanding the institutional environment also develop students' sense of belonging (Honkimaki \& Kalman, 2012) 


\section{Way Forward}

The study showed that the traditional model of sending information about orientation programs was not feasible for students from rural and poor backgrounds due to their immense transitional needs. Perhaps such institutions should consider using alternative models such as first year seminars or extended orientation where a small number of credits are attached to students' participation in weekly seminars covering various topics that deal with issues of transition. These seminars can be facilitated by specialists from different disciplines. To this end, inclusion of various academic staff to teach some of the topics during orientation seminars is a strategy for enhancing prolonged students- staff interaction which could richly enhance academic intergration. Also, the insitutions may consider changing their modes of communication to ensure that information on orientation reaches out to all their clients. Also, it may be important to develop an institution based strategy in which stakeholders could be left to deal with the design of orientation programs, particularly making all staff actively participate in the designing of the program activities so as to own the program goals.

\section{Conclusion}

Undoubtedly, findings from the study reveals that there are complex and interelated impediments in isnstitutional orientation programs. Specifically, findings from this study indicate that orientation programs are serving a small proportion of the student population. This was attributed to both students and institutional factors. For that reason, if orientation is to adequately achieve its goals, operations and conceptualisation of the program at insitutonal level, it needs to undergo a paradigm shift, particularly in terms of communication and timing of the program.. This is because the tradition model that is currently being used provides limited opportunites for students to acclimitise as well as develop basic metacognitive and phychological dispositons that enhance student success and retention . It might be critical to consider increasing the the orientation time frame to provide for increased increased interaction among themselves and with various insitutional structures and stakeholders. Importantly, further research may be required to find out which alternative orientation models would be suitable for the South African higher education context. Since the South African higher school system is still blamed for the high student dropout, the solution may not soley lie with improving orientation programs, but also to relook at improving other programs that would expeditiously address cultural, psychological and social needs of students who come from disadvantaged backgrounds.

\section{References}

Babbie, E. (2010). The Practice of Social research. (12th Ed). Belmont. Cenard Learning.

Bergman, M. (2008). Advances in Mixed Methods Research: Theories and Application. London : SAGE.

Creswell, J. (2009). Research Design: Qualitative, Quantitative and Mixed Methods Approches (3 ed.). Thousand Oaks: SAGE.

Crossling, G.,Thomas,L., Heagney,M. (2008). Improving student retention in higher education. Australian Higher Education Review, 51 (2), 9-18.

Department of Higher Education Act 101 of 1997 (2005): Minimum Admission Requirements for Higher Certificate, Diploma and Bachelor's Degree Programmes Requiring a National Certificate. Pretoria. Department of Education

Drew, C.J.,Hardman,M.C., \& Hoop, J.L. (2008). Designing and Conducting Research in Education. London: SAGE .

Honkimäki, S. \& Kálmán,O. (2012). Approaches to Transition support for First year students in Higher Education. In P. Tynjala, Transitions and Transformations in Learning and Education (Vol. 1, pp. 247-271). Springerlink Science and Bussiness Media.

Johnson, B. \& Christensen, L. (2012). Educational Research: Quantitiative, Qualitative and Mixed Approaches. (4th Edition ed.). Far East Square: SAGE Publications.

Kuh, G. D. (2008). High impact practices. What are they, who has access to them and why they matter. Washington: Association of American Colleges and Universities.

Kramer, G.L.,Washburn,R. (1983). Percieved orientation needs of new students. 24 (4), 311-319.

Letseka,M.,Breier,M. (2007). Student dropout in higher education. The impact of higher education drop out on poverty. Ch 6. 83-101. 86101.

Leedy, P. \& Ormrod, J. (2010). Practical Research: planning and design (10th ed.). Thousand Oaks:New Jersey: SAGE Publications.

Longden, B. (2004). Interpreting students early departure from higher education through the lense of cultural capital. Tertiary Education and Management, 10, 121-138., 121-138

Maree, K. (2007). First Steps in Research (1st Edition ed.). Pretoria: Van Schaik Publishers.

Martinez, P. (1997). Improving Student Retention: A guide to successful strategies. London: Further Development Agency.

Mayhew, M.J.,Vanderlinden,K.\& Kim,E.K. (2010). A multi level assessment of the Impact of Student Orientation Programmes on Student Learning. Research on Higher Education , 51, 320-345.

Modipane, M. (2011). Initial experiences of first entering students at the University of Limpopo: Implications for coping with studies. South African Journal on Higher Education , 25 (8), 1592-1607. 
Mullendore, R.H.,\& Banahan, L.A. (2005). Designing orientation prgrammes. In M. J. Upcraft, Challenging the first year student. National Resource Centre for the First Year Experienc and student transition.

Newman-Gonchar, R. A. (2000). Role of orientation programmes in guiding student transition to college. Journal of student affairs , 1-8. Pascarella, E.T., \& Terrenzini, P.T. (2005). How College Affects Students: A Decade of Research (Vol. II). San Francisco: Jossey Bass. Solzhenitsym, A. (2008, Feb 2). Five big ideas for freshmen orientation. Casting out Nines .

Strydom, J.F., Basson, N.\& Mentz, M. (2010). Enhancing the quality of teaching and learning: Using Student Engagment data to establish a culture of evidence. Pretoria: Council on Higher Education.

Silverman, D. (2011). Qualitative Research:Issue of Theory Methods and Practice (3rd ed.). London: SAGE.

Tinto, V. (2005). Reflections on retention and persistence : institutional actions on behalf of

student persistence. Studies in Learning, Evaluation, Innovation and Development, 2 (3), 9-97.

Tashakkori, A. \&Teddlie, C. (2009). Mixed methodology: Combining qualitative and quantitative approaches. Applied Social Research Methods Series (Vol. 46). Thousand Oaks, CA: SAGE Publications.

Thomas, L.,Quinn, J.,Slack, K., Casey, L. (2012). Effective Approaches to retaining students in Higher Education. Stoke on Tent: Institute For Access. Staffordshire University.

Thomas, L.,\& Quinn,J. (2006). First generation Entrants in Higher Education. An International Analysis. Maidenhead: Society for Research in Higher Education and Open University Press

UNESCO. (2002). The role of student affairs and services in Higher Education:A Practical manual for developing, implementing and evaluating student affairs programs and services. Paris: UNESCO.

Upcraft,M.I., Gardiner, J, N., Barefoot, B.O. (2005). Challenging and Supporting the first year student. A handbook for improving the first year of college. San Francisco: John Willey \& Sons. 